\title{
EL SIGNO EN SPINOZA: IMÁGENES, PALABRAS E IDEAS
}

\author{
Maribel Barroso Rojo ${ }^{1}$ \\ Universidad Alberto Hurtado, Chile
}

\begin{abstract}
Resumen: Se expone la relación entre el signo en tanto gnoseológica y semánticamente subordinado a la imaginación y el uso del lenguaje como medio para expresar las verdades filosóficas por parte de Spinoza. Al respecto, se revisan tres posturas: (i) la de David Savan, quien sostiene la inadecuación del lenguaje para expresar verdades filosóficas debido a la vinculación spinoziana entre las palabras y la imaginación; (ii) la de G.H.R. Parkinson, quien afirma que el uso del lenguaje no es inconsistente con la expresión de las proposiciones filosóficas por parte de Spinoza, sino que, la mayor parte de lo propuesto en la Ética pertenece al conocimiento de razón y las nociones comunes y; (iii) la de Mogens Laerke, quien defiende la posibilidad de atribuir coherencia al uso del lenguaje, por un lado, y a la filosofía spinoziana, por el otro, a partir del recurso matemático de la demostración geométrica. Finalmente, se argumenta una interpretación propia con base en el análisis semiótico del signo en Spinoza, a partir de la cual (i) es posible atribuirle al signo una función dentro del entendimiento, sin detrimento de su capacidad gnoseológica y semántica para alcanzar verdades filosóficas y, por consiguiente, (ii) validar el uso del lenguaje como medio para expresar su filosofía.
\end{abstract}

Descriptores: Lenguaje $\cdot$ Signo $\cdot$ Imaginación $\cdot$ Entendimiento $\cdot$ Idea verdadera.

Abstract: The paper explains the relationship between sign as gnoseologically and semantically subordinated to imagination and the use of language as means of expressing philosophical truths. Then, three positions are reviewed: (i) David Savan, maintains the inadequacy of language to express philosophical truths due to Spinoza's link between words and imagination. (ii) G.H.R. Parkinson, states that the use of language is not inconsistent with Spinoza's expression of philosophical propositions, since most of what is proposed in Spinoza's Ethics belongs to knowledge of reason and common notions. Finally, (iii) Mogens Laerke defends the possibility of attributing coherence to the use of language, and to Spinoza's philosophy, from the mathematical resource of geometrical proof. Finally, we give our own interpretation based on the semiotic analysis of sign in Spinoza, from which (i) it is possible to attribute to the sign a function within the understanding, without detriment to its gnoseological and semantic capacity to reach philosophical truths and, consequently, (ii) to validate the use of language as a means to express his philosophy.

Keywords: Language $\cdot$ Sign $\cdot$ Imagination $\cdot$ Understanding $\cdot$ True Idea.

Enviado: 02/11/2020. Aceptado: 11/12/2020

\footnotetext{
${ }^{1}$ Programa de Doctorado. E-mail: $\underline{\text { mbarroso@alumnos.uahurtado.cl }}$
} 
Tanto en Ética demostrada según el orden geométrico (en adelante $E)^{2}$ como en el Tratado de la Reforma del Entendimiento (en adelante TRE), Spinoza manifiesta que su propósito consiste la consecución de un modo de vida orientado al verdadero bien, esto es, a "aquello que es medio para alcanzar el carácter humano perfecto; siendo el sumo bien el goce del hombre junto a otros hombres de ese carácter" (TRE, §13); para lo cual resulta una tarea esencial la de curar o purificar el entendimiento, esto es, "hacerlo apto para entender las cosas tal y como es necesario para conseguir la suma perfección humana" (TRE, §16). El camino a recorrer en este sentido consiste en la búsqueda de ideas claras y distintas, formadas por el entendimiento y no a partir de los movimientos del cuerpo (TRE, §86), así como en la reconducción de todas las ideas a una sola que se perciba por su propia esencia, esto es, que no requiera de una causa para existir. (TRE, §95). Esto llevó a pensar a Herman De Djin que el corazón del método spinoziano es de naturaleza gnoseológica, ya que, por un lado, éste básicamente reside en el conocimiento reflexivo de la naturaleza y en el poder del intelecto, mientras que, por el otro, en el alejamiento de las ideas formadas a partir de los cuerpos, luego, de la imaginación.

Como es sabido, gnoseológicamente Spinoza distingue tres géneros de conocimientos o modos de percibir, a saber: (i) el conocimiento de opinión e imaginación o 'primer género de conocimiento', que consiste en dos modos de percibir: (a) a partir de la experiencia vaga, esto es, “(...) a partir de cosas singulares que nos son representadas por los sentidos de forma mutilada, confusa y sin orden al entendimiento (...)"; (b) a partir de signos, esto es, "que al oír o leer ciertas palabras, recordamos las cosas y formamos de ellas algunas ideas semejantes a aquellas con que solemos imaginarlas" (E2p40esc2); (ii) el conocimiento de razón, también llamado 'segundo género de conocimiento' que corresponde al conocimiento de las 'nociones comunes' e 'ideas adecuadas' de las cosas, y (iii) el conocimiento intuitivo o 'tercer género de conocimiento', el cual "procede de la idea adecuada de la esencia formal de algunos atributos de Dios". La verdad se encuentra directamente en el conocimiento intuitivo e indirectamente en el conocimiento de razón, mientras que, el conocimiento imaginativo es causa de la falsedad, la inadecuación y la confusión (E2p41esc2). ${ }^{3}$

\footnotetext{
${ }^{2}$ Agregamos página y escolio.

${ }^{3}$ En el TRE hace, mutatis mutandis, una caracterización similar, con la diferencia de que en lugar de tres géneros de conocimiento nombra cuatro (Cf. TRE, §19-22); y dice del tercer género de conocimiento (segundo en la Ética) que este: “...de algún modo nos proporciona la idea de la cosa” y que gracias a este "...concluimos sin peligro de error. Pero no será por sí mismo el medio para adquirir nuestra perfección. Tan solo el cuarto modo (*o en la Ética) comprende la esencia adecuada de la cosa y sin peligro de error, por esa razón deberá usarse principalmente" (TRE, § 28-29).
} 
Si el conocimiento de razón nos aproxima al conocimiento verdadero, mientras que, el conocimiento intuitivo es necesariamente verdadero, resulta razonable preguntar ¿a qué tipo de conocimiento corresponde el entendimiento? Según Paul Eisenberg (1971), p.184, Spinoza no atribuye el entendimiento a los dos primeros tipos de percepción del TRE, a saber, la percepción de oídas y experiencia vaga o, de acuerdo a la Ética, el conocimiento de opinión o imaginación. Solo el conocimiento intuitivo puede asociarse con el entendimiento y, en un sentido derivativo, el conocimiento de razón. El motivo del rechazo al conocimiento de razón es que el conocimiento que se obtiene de ese modo es abstracto o general, es conocimiento de las propiedades de las cosas y no de sus esencias. De acuerdo con Eisenberg, el repudio de Spinoza a la realidad de las abstracciones, de los géneros y las especies tradicionales, lo lleva a afirmar un "nominalismo intransigente" según el cual, las únicas cosas reales son las particulares, como aquel o este hombre, e insiste en que las cosas particulares tienen esencias tan individuales y tan únicas, como las cosas mismas. Luego, la insatisfacción de Spinoza con el conocimiento de razón es que, al ser un conocimiento de cosas particulares, se expresa, sin embargo, en el lenguaje de abstracta et universalia.

En efecto, las palabras, en tanto signos de ideas que refieren a seres y a cosas de manera abstracta, son llamados por el filósofo holandés 'términos trascendentales', cuando estos 'tienen su origen en el hecho de que el cuerpo humano, por ser limitado, sólo es capaz de formar en él cierto número de imágenes (...) distintas y simultáneas", siendo que, si se sobrepasa el número de imágenes que el cuerpo es capaz de formar, las mismas "comenzarán a confundirse; y, si el número de imágenes que el cuerpo es capaz de formar en él simultánea y distintamente, es muy superado, se confundirán todas completamente unas con otras" (E2p40esc1b); mientras que, son denominados 'términos universales', palabras como 'hombre', 'perro' y 'caballo'. La idea de hombre para Spinoza, por ejemplo, viene de las muchas veces que el cuerpo humano es superado en su capacidad de ser afectado por imágenes de hombres (E2p40esc1c). Ambos tipos de términos, los trascendentales y los universales, son, pues, confusos e inadecuados.

Sabemos que en relación al conocimiento de razón y al conocimiento intuitivo, el entendimiento ejerce un papel activo en la gnoseología spinoziana; pero ¿qué sucede con el conocimiento de opinión e imaginación?, ¿cuál es su relación con el entendimiento? Sus objetos, entre los cuales se encuentran los signos lingüísticos, ¿pueden ser objetos, a su vez, del entendimiento?, en otras palabras, ¿es posible trasmitir ideas verdaderas a partir del lenguaje? Con el propósito de mostrar la dificultad que subyace al uso del lenguaje en Spinoza para expresar su filosofía, en el presente trabajo se revisan tres interpretaciones que representan las posiciones de los comentaristas de Spinoza al respecto: (i) la que sostiene que el 
lenguaje es inadecuado para expresar verdades filosóficas por estar vinculado con el conocimiento de opinión e imaginación, (ii) la que asevera que el uso del lenguaje por parte de Spinoza, no es inconsistente con la expresión de sus proposiciones filosóficas, sino que, por el contrario, la mayor parte de lo propuesto en la Ética pertenece al conocimiento de razón y las nociones comunes y, (iii) la que se apoya en el recurso matemático de la demostración geométrica para defender la posibilidad de atribuir coherencia al uso del lenguaje y la filosofía spinoziana. Tales interpretaciones se encuentran en los trabajos de David Savan (1972), G.H.R. Parkinson (1969) y Mogens Laerke (2014), respectivamente.

Finalmente, con apoyo de la concepción tríadica del signo de Charles $\mathrm{S}$. Pierce se propone una interpretación propia que busca dar cuenta del tránsito del lenguaje en Spinoza desde su origen en la imaginación hasta ser una idea en el entendimiento, atribuyéndole un rol no solo en la imaginación, sino, además, dentro del ámbito de la razón, sin menoscabo de su capacidad para alcanzar verdades filosóficas y, por consiguiente, reivindicar su uso como medio adecuado para exponer su filosofía.

\section{TRES INTERPRETACIONES: SAVAN, PARKINSON Y LAERKE}

En "Spinoza and Language", David Savan defiende la tesis de que lejos de pretender que la Ética fuese una simple exposición de las verdades filosóficas, Spinoza se proponía mostrar en ella las limitaciones del lenguaje. $\mathrm{Su}$ argumentación gira en torno a dos tesis: (i) que el lenguaje es un medio inapropiado para expresar las verdades filosóficas de la Ética y (ii) que Spinoza era consciente de ello. Visto en detalle:

(i) que el lenguaje es un medio inapropiado lo deduce del hecho de que las palabras, según Savan (1972), p. 237: "no son más que movimientos corporales" en respuesta a "la acción sobre él de los cuerpos externos" y en tanto, "la idea de tal movimiento será mutilada, confundida e inadecuada, ya que solo se puede entender de manera apropiada junto con las ideas de los movimientos externos que lo indujeron". Por consiguiente, como no conocemos su causa, suponemos que éstas se encuentran incausadas o bien las explicamos teleológicamente. Ambas posibilidades son rechazadas por Spinoza, argumenta Savan (1972), p. 238: “El carácter imaginativo, general y confuso de las palabras no es, a juicio de Spinoza, contingente ni accidental. No es el resultado de la ignorancia y no puede ser eliminado por el conocimiento" (Traducción propia). Trasmitir las verdades filosóficas por medio del lenguaje es tan eficaz como la comunicación inteligible del sonámbulo con el mundo real, comenta con ironía Savan. 
(ii) la inadecuación del lenguaje es algo que Spinoza señala "enfática y repetidamente en la mayoría de sus escritos" a través de la expresión de contradicciones. Estas contradicciones son de acuerdo a Savan (1972), p. 240:

(a) aquellas que surgen del intento de definir en palabras la naturaleza de la entidad única, la sustancia; (b) aquellas que surgen del intento de definir o describir las propiedades únicas de la sustancia; y c) aquellas que surgen de intentos de definir o describir modos o esencias modales. (Traducción propia).

La primera refiere al uso de términos trascendentales y universales para referirse a la sustancia y a Dios, tales como "ser", "concebir", respectivamente. La segunda tiene que ver con las afirmaciones contradictorias de Spinoza al referirse a Dios como "único y simple", por un lado, mientras que, por el otro, dice Savan (1972), p. 242: "Es cierto que el que llama a Dios uno o único no tiene una idea verdadera de Dios, o está hablando de él inapropiadamente. O cuando dice "Dios no ama a nadie", pero luego dice "Dios se ama a sí mismo" y "Dios (...) ama a los hombres". Por último, las que surgen al explicar los modos a través de propiedades definidas para la natura naturans y en otras ocasiones, a través de propiedades aplicadas a la natura naturata".

De lo anterior, Savan concluye que Spinoza estaba tan preocupado en vincular las palabras y, por ende, el lenguaje, al ámbito confuso y equívoco de la imaginación, que no se dio la tarea de explicar cómo éstas pueden trasmitir las verdades filosóficas. Esto, reconoce, puede ser un argumento en contra de su tesis de que Spinoza conocía tal inadecuación del lenguaje. Sin embargo, señala que la clave para comprender tanto la Ética, como sus otros escritos sobre ciencia natural, gramática hebrea y bíblicos, se encuentra en su noción de “entes de razón”. Explica Savan (1972), p. 245:

Puesto que los entes de razón son (...) funciones de la imaginación, las palabras tienen un papel adecuado que desempeñar en su formulación. En particular, los entes de razón de la filosofía como la distinción entre la esencia y la existencia de Dios, el poder y otras propiedades, género y especie, los trascendentales, las modalidades, las nociones del no ser, oposición, orden, relación, conjunción, accidente, perfección, el bien y el mal -todo esto surge a través de comparaciones verbales de modos que se nos dan a través de la imaginación. (Traducción propia).

Ningún purgativo puede eliminar la generalidad imaginativa y confusa de las palabras, es por ello que la tarea de la Ética, en su opinión, consiste primordialmente en mostrar las limitaciones del leguaje para concebir la sustancia y sus modos. Los filósofos han sido particularmente propensos, por lo tanto, a dos tipos de error: (i) a menudo han dado descripciones verbales inadecuadas o engañosas de sus entes de razón; (ii) peor aún, al no distinguir la imaginación del intelecto con suficiente 
claridad, han planteado que las palabras que utilizaron eran nombres de entidades existentes fuera del lado del intelecto, concluye Savan (1972), pp. 245-246.

Por su parte, G.H.R. Parkinson (1969) responde larga y extensamente a Savan en su ensayo "Language and Knowledge in Spinoza". Allí, Parkinson sostiene que las dos tesis de Savan son incorrectas: (i) que las opiniones de Spinoza sobre el lenguaje no tienen las consecuencias lógicas que afirma Savan, y (ii) que Spinoza no creía que tuvieran estas consecuencias. Su argumentación parte de dos argumentos centrales: (i) que Spinoza pudo haber distinguido entre dos tipos de imaginación que corresponden a lo que sería la distinción kantiana entre imaginación trascendental e imaginación empírica (cf. Crítica de la Razón Pura A115-25; B80-81, 151-2), y (ii) que la mayoría de las proposiciones de la Ética corresponden al conocimiento de razón y, en consecuencia, que el uso de palabras como "nociones comunes" es viable para expresar las verdades filosóficas.

Un argumento clave para entender la posición de Savan, señala Parkinson (1969), p. 18, es la consideración del primero de que "en casi todos los aspectos importantes, Spinoza opone las ideas verdaderas a las palabras"; de acuerdo con su interpretación, agrega Parkinson, una idea no es una imagen, ni una palabra: mientras las palabras son generales y plurales, las ideas "y sus ideatas" son simples y singulares. Savan se apoya en los distintos pasajes en los que Spinoza vincula las palabras con la imaginación o en los que establece una distinción entre palabras y entendimiento, para dar cuenta de que no hay manera de hablar con verdad a través del lenguaje. No obstante, de acuerdo a Parkinson, no está tan claro que de estos pasajes se siga necesariamente que las palabras constituyan un medio inapropiado para expresar las verdades filosóficas, ya que la imaginación no solo está determinada por la constitución del cuerpo sino además por la constitución del alma. Spinoza en cita de Parkinson (1969), pp. 20-21, dice:

Debido a que (...) en todas las cosas [la imaginación] sigue las huellas del intelecto y concatena sus imágenes y palabras en un cierto orden (ex ordine), y las interconecta, (...) no hay casi nada que podamos entender de lo que la imaginación no forma alguna imagen o huellas de la misma.

Si bien las palabras surgen de la experiencia y, por consiguiente, se encuentran estrechamente vinculadas a la imaginación, también pueden seguir las huellas o el orden del entendimiento, y en tal sentido, asociarse con ideas adecuadas. Llama la atención de Parkinson que en algunos pasajes Spinoza atribuye al mismo modo de conocer: los objetos de la imaginación, las demostraciones deductivas y la denotación de la fruta por la palabra 'manzana', por ejemplo. Sugiere entender la imaginación en Spinoza como una noción bipartita, similar a los dos tipos de imaginación kantianos, a saber, una imaginación trascendental, a priori y necesaria; 
y una imaginación empírica, de naturaleza inductiva (Parkinson G., 1969, p. 22). De la carta 17 también concluye que Spinoza consideraba que el pensamiento y las palabras eran dos cosas distintas, siendo las palabras signos en el pensamiento -aunque aclara que pensar no es solamente usar palabras-. Por otra parte, Parkinson recuerda que, de acuerdo a Spinoza, las palabras se refieren tanto a ideas como a cosas (Cf. E2p40esc y E2p49esc).

La segunda parte de la crítica de Parkinson a Savan consiste en aclarar lo que a su juicio es un hecho, a saber, que Spinoza no rechaza todo tipo de palabras, sino solo dos: los términos trascendentales y los universales. Nada parece impedir la denotación de individuos mediante nombres propios para Parkinson. Sin embargo, acepta que Spinoza no sólo utiliza nombres propios en la Ética, sino que ocupa también términos trascendentales y universales para definir, por ejemplo, a Dios como "un "ser absolutamente infinito" (E1def6); o cuando utiliza el término “concebir" para definir la sustancia (E1def3). Parkinson tiene dos cosas que decir al respecto. En primer lugar, que lo anterior no es prueba de que el lenguaje sea inapropiado para expresar las verdades filosóficas en Spinoza, aunque sí, desde luego, pone en duda las competencias lógicas del filósofo holandés y, en segundo lugar, que Spinoza no consideraba objetable todos los usos de palabras como "ser" y "concebir", o usando su propio ejemplo, la palabra "cosa", sino que, dice Parkinson (1969), pp. 23-24:

Parece mucho más probable que Spinoza afirme que el concepto de una cosa, como se utiliza en esta definición, es lo que él llama una "noción común". Según Spinoza, «las cosas que son comunes a todos, y que son iguales tanto en la parte como en su conjunto, solo pueden concebirse adecuadamente» (Ética 2P38); estos conceptos adecuados son lo que él llama "nociones comunes" (Ética. 2P38Cor, 2P40Schl y Sch2), y son, en parte, la base de la "razón", su "segundo tipo de conocimiento" (...). El alegato de que las definiciones de Spinoza contienen términos universales del tipo al que se opuso puede responderse esencialmente de la misma manera. (Traducción propia).

De acuerdo con Parkinson (1969), p. 25, es un error considerar que "una idea no es una imagen y no consiste en palabras" ya que, si bien Spinoza aconseja distinguir entre ideas e imágenes, no afirma que no tenemos ideas al imaginar, sino que, más bien, está afirmando, implícitamente, que no sólo tenemos ideas al imaginar, sino que también hacemos juicios, esto es, afirmamos o negamos proposiciones en la mente. De manera que el tipo de conocimiento implicado en el conocimiento de las proposiciones de la Ética es el conocimiento de razón, por consiguiente, las ideas que son su objeto, en tanto conocimiento verdadero, no son otras que las llamadas "nociones comunes", que, dice Parkinson (1969), p. 34: 
Son, como su nombre lo indica, ideas o nociones comunes a todos los hombres (E2P38Cor), por lo que deben distinguirse de aquellos conceptos universales que varían de persona a persona y que Spinoza relega al primer tipo de conocimiento. (Traducción propia).

Estas ideas serían adecuadas o verdaderas. Ejemplo de ellas son las ideas y los conceptos de las ciencias naturales, como, por ejemplo, las de la física que, si bien son generales, son también claras y unívocas. Parkinson se apoya en el siguiente pasaje de la Ética (E2P44Cor2): :

[L]os fundamentos de la razón son nociones (por 2/38), que explican aquello que es común a todas las cosas y que (por 2/37) no explican la esencia de ninguna cosa singular; y, por tanto, deben ser concebidas no en relación alguna con el tiempo, sino bajo alguna especie de eternidad.

Un intérprete que ha retomado recientemente la discusión sobre el tema del lenguaje en Spinoza es Mogens Laerke. En su artículo “Spinoza’s Language”, Laerke (2014) recoge dos tipos de posiciones respecto a la discusión sobre la relación entre el lenguaje y la filosofía en Spinoza, a saber, el enfoque externalista, cuyos argumentos para explicar la opacidad del lenguaje en los escritos de Spinoza se encuentran fuera de la propia filosofía spinoziana, y el enfoque internalista, que apela, a tal fin, a cuestiones propias de su filosofía. Como ejemplo del primer enfoque, Laerke considera la opinión de Stuart Hampshire, quien sostiene que la oscuridad del lenguaje en Spinoza es resultado del miedo a ser perseguido. Como representantes del enfoque internalista menciona al mismo Savan, al que dedica buena parte de sus líneas con el objeto de refutar sus tesis, a François Zourabichvili, a quien le atribuye una opinión casi mística de la filosofía de Spinoza y, por último, a Edwin Curley, cuya opinión representa un punto medio entre los dos anteriores, pero que, sin embargo, no llega a dimensionar en su justa medida el revisionismo spinoziano.

En todo caso, Laerke prefiere este último enfoque, el internalista, y se propone argumentar (i) contra las tesis de Savan y (ii) en favor del método geométrico como base de la reconstrucción sistemática del lenguaje filosófico en Spinoza. En cuanto a (i) su crítica pone el foco en la interpretación de Savan sobre la inadecuación del lenguaje para la filosofía spinoziana, cuyo origen encuentra en: (a) una mala interpretación del papel de la imaginación en la gnoseología spinoziana, ya que no está claro que un adecuado lenguaje filosófico requiera per se una conexión entre las palabras y el intelecto sin intervención de la imaginación; después de todo, la imaginación no es más que el lugar en el cual la mente registra las huellas que el mundo externo deja en nuestros cuerpos, y en tal sentido, es indiferente al error y la falsedad. Enfatiza Laerke (2014), p. 525: "De hecho, de acuerdo con E2p17s, si nuestra imaginación es interpretada correctamente por el intelecto, la mente 
incluso "atribuye este poder de imaginar a una virtud de su naturaleza, no a un vicio"". Por consiguiente, el asunto aquí es cómo construir un lenguaje que refleje una imaginación guiada por el entendimiento; y (b) en pasar por alto las "nociones comunes" y explicar los términos generales que Spinoza utiliza en la Ética como términos trascendentales y universales. Los pasajes que Savan cita para exponer las supuestas contradicciones de Spinoza sugieren, más bien, que es posible asignar distintos significados a la misma palabra en diferentes contextos. Así, la palabra 'hombre' puede referir en algunos casos a una noción universal y, por lo tanto, ser inadecuada; mientras que, en otros, puede significar una definición adecuada o noción común del hombre.

Por otra parte, Laerke llama la atención sobre el hecho de que las preocupaciones de Spinoza por el lenguaje tienen menos que ver con la expresión de su filosofía, que con la memoria colectiva de los pueblos y sus representaciones políticas y culturales; dice Laerke (2014), p. 526: “(...) los pensamientos más elaborados sobre el lenguaje no están en la Ética, sino en el TTP, donde encontramos varias reflexiones especialmente sobre el estado, la constitución y la transmisión del hebreo bíblico". Reparando en que mientras en el TTP Spinoza muestra cómo la Escritura acomoda la Palabra Divina a la comprensión de la gente, Spinoza en la Ética busca enseñar a la gente a hablar de manera divina de las cosas humanas. Claramente las palabras se encuentran conectadas por cadenas de asociaciones distintas adquiriendo significados de acuerdo a su uso, concluye Laerke. La tarea del filósofo es hacer que el lenguaje represente el orden del entendimiento y no el de la imaginación, con el auxilio del modo geométrico, cuya función en la Ética consiste, no solo en ordenar las palabras de acuerdo al entendimiento, sino otorgar a través de sus axiomas, definiciones, proposiciones y escolios, nuevos significados acorde con el entendimiento y así, hablar de manera divina de lo humano.

\section{EL SIGNO: IMÁGENES, PALABRAS E IDEAS}

El intérprete Lorenzo Vinciguerra ha llamado la atención respecto al hecho de que los intérpretes de Spinoza no se han detenido a preguntar, al menos no explícitamente, qué tenía en mente Spinoza cuando hablaba de signos, señalando que, por lo general, estos tienden a realizar su interpretación del lenguaje en Spinoza desde una perspectiva tradicional que conecta el significado con el cuerpo de acuerdo a una doctrina tripartita platónica del alma, según la cual, el lenguaje se encuentra vinculado a las facultades mentales del ser humano y no, a la extensión y al pensamiento como dos atributos de una misma y única sustancia desde la perspectiva spinoziana. (Vinciguerra (2012), p.134). 
Ciertamente, la ontología spinoziana dejó huella en su epistemología como defiende Vinciguerra a lo largo de su ensayo. En particular, en su teoría de la imaginación. Requiriendo con ello, un cambio de perspectiva. En lugar de entender, como lo hacen los intérpretes Savan, Parkinson y Laerke, el lenguaje en Spinoza como una práctica cuya lógica interna se agota en el significado, con las discrepancias a que estas interpretaciones conducen; en lo que sigue, se propone una interpretación del signo en Spinoza que incorpore la dimensión pragmática del lenguaje con base en la lógica externa de su uso en tanto marcas o vestigios del cuerpo.

En cierta manera, entender es padecer, como comenta Aristóteles ( $D A$, III, 429a10). ${ }^{4}$ Spinoza no solo estaría de acuerdo con el filósofo, sino que, además, añadiría que las palabras, en tanto tienen su origen en las afecciones del cuerpo, son un síntoma de ello. Spinoza no llega a ejemplificar cómo el entendimiento puede llegar al conocimiento de las cosas eternas en el TRE por razones obvias. Tampoco lo hace en la Ética, en la que más bien repara:

De qué modo, sin embargo, y por qué vía debe ser perfeccionado el entendimiento y con qué arte, además, debe ser curado el cuerpo para que pueda cumplir rectamente su oficio, no pertenece a este lugar, puesto que esto concierne a la Medicina* y aquello a la Lógica* (E5prólA).

Corresponde entonces, según Spinoza, a la lógica, esto es, al método ${ }^{5}$ dar cuenta de cómo debe ser perfeccionado el entendimiento. Sin embargo, es sabido que el entendimiento es concebido por Spinoza como una facultad o modo de pensar, cuya función consiste en percibir los atributos de la sustancia y no la sustancia en sí misma (Cf. E1def4). Así, dice en E1p31dem:

Por entendimiento no entendemos, en efecto (como es por sí mismo evidente), el pensamiento absoluto, sino tan sólo cierto modo del pensar, el cual difiere de otros, a saber, del deseo, el amor, etc. Y, por tanto (por 1/d5), ese modo debe ser concebido por el pensamiento absoluto, es decir (por $1 / 15$ y l/d6), por un atributo de Dios que expresa la esencia eterna e infinita del pensamiento; y de tal modo

\footnotetext{
${ }^{4}$ Se utiliza la edición de Immanuel Bekker, Aristotelis Opera, Vol. I, Berlín, Academia Regia Borussica, 1831 [http://ia700500.us.archive.org/7/items/aristotelisopera01 arisrich/aristo-telisopera01 arisrich bw.pdf] para la numeración de las citas textuales.

${ }^{5}$ Andrey Maidamsky señala en su artículo "The reform of Logic in Descartes's and Spinoza's Works", que Descartes inició una verdadera reforma de la lógica, su Mathesis Universalis estudia el orden único de la naturaleza en su forma pura, esto es, cómo el método del verdadero orden. A diferencia de la lógica tradicional, que era un instrumento de la metafísica, el orden de la naturaleza debe ser construido a partir de categorías de la razón y de acuerdo a causas y efectos, y no de acuerdo al esquema formal de género y especie. Maidamsky afirma que Spinoza apoyó y continuó totalmente los esfuerzos en reformar la lógica que inició Descartes, y que, en tal sentido, también se esforzó en convertir la lógica en una disciplina sobre objetos. Agrega que la expresión spinoziana "true logic" es indicador de que él nunca confundió la lógica como tal, con la lógica tradicional que era expuesta en los manuales de la época. (Maidansky, 1998).
} 
debe ser concebido que no pueda ser ni ser concebido sin él. En consecuencia (por 1/29e), debe ser referido a la Naturaleza naturada y no a la Naturante, e igualmente los demás modos del pensar.

De lo anterior se infiere que el entendimiento, y la mente concebida como atributo del pensamiento absoluto, son dos cosas distintas, siendo más amplia la mente que el entendimiento en cuanto modo de pensar. No obstante, esta afirmación puede ser un tanto apresurada, ya que las nociones de entendimiento y mente no son precisamente claras en la filosofía spinoziana. La noción de entendimiento en Spinoza es menos que confusa. A menudo identifica el entendimiento con la mente, mientras que otras veces diferencia a ambos; aunque, dice Eisenberg (1971), p. 178:

[Q]ue esto último es su verdadera doctrina y que no simplemente vacila entre un punto de vista y el otro, se indica por el hecho de que Spinoza, aunque algunas veces se acerca a decir (...), nunca dice realmente que el intelecto contiene o puede contener impurezas imaginativas dentro de sí mismo, aunque ciertamente dice que la mente puede contener o normalmente contiene tales impurezas; y aunque a menudo contrasta intellectus (o intellectio) con imaginatio, nunca contrasta (por ejemplo) mens con imaginatio.

Bajo el supuesto de que entendimiento y mente son dos cosas distintas, a través de la semiología como ciencia del signo, se pueden conseguir indicios para una interpretación adecuada del uso por parte de Spinoza de las imágenes, las palabras y las ideas. La definición de signo que se utiliza en este sentido es la de Pierce (1974), p. 23: "La palabra Signo será usada para denotar un Objeto perceptible, o solamente imaginable, o aún inimaginable en un cierto sentido". Como es sabido, la semiótica distingue entre signos, por un lado, e imágenes, palabras e ideas, por otro; siendo el signo, en tanto ícono, índice y símbolo, la unidad básica del análisis semiótico (Cf. Pierce, 1974, págs. 45-62). Para representar la relación triádica entre el signo, la idea y el objeto al que refiere, se distinguen tres ámbitos, a saber: el sintáctico, en tanto el signo se relaciona con otros signos; el semántico, en tanto el signo es portador de significado y el pragmático, en tanto el signo es interpretado. Esta distinción disciplinar, aunque ajena a la época en que escribió Spinoza, puede ser útil para entender en el presente su tratamiento, implícito, del signo en tanto imágenes, palabras e ideas. Dice Spinoza en la Ética:

Comienzo, pues, por el primer punto, y advierto a los lectores que distingan con precisión entre la idea o concepto del alma y las imágenes de las cosas que ellos imaginan. Es necesario, además, que distingan entre las ideas y las palabras con las que significamos las cosas. Pues, como muchos, o bien confunden totalmente 
estas tres cosas, a saber, las imágenes, las palabras y las ideas, o bien no las distinguen con suficiente precisión $\mathrm{o}$, en fin, con la debida cautela ${ }^{6}$, ignoran completamente esta doctrina sobre la voluntad, que es imprescindible conocer tanto para la especulación como para ordenar sabiamente la vida (E2p49escC).

La distinción spinoziana entre las palabras y las ideas, es sostenible desde la semiótica, toda vez que el signo en cuanto palabra: (i) se relaciona con otras palabras formando un lenguaje; (ii) representa o significa una idea y; (iii) es ocupado de una o distintas maneras, por uno o distintos intérpretes; formando así una relación triádica entre los ámbitos sintáctico, semántico y pragmático, respectivamente; mientras que, desde un primer momento posee la cualidad representativa de la Primeridad, esto es, según Pierce (1974), p. 46:

es una imagen de su objeto y para expresarlo más estrictamente. sólo puede ser una idea, porque debe producir una idea Interpretante; y un objeto externo provoca una idea mediante una reacción sobre el cerebro. Para decirlo con el mayor rigor, es imposible que aún una idea sea un Icono, excepto en el sentido de una posibilidad, o Primeridad.

En esta fase el signo se comporta como Ícono, ${ }^{7}$ esto es, como la representación perceptible de una imagen. Luego están el signo como Índice ${ }^{8}$ y el signo como Símbolo, ${ }^{9}$ considerando al primero en el orden de la Segundidad, según Pierce (1974), p. 86: "el modo de ser de aquello que es tal como es con respecto a una segunda cosa, pero con exclusión de toda tercera cosa" y el segundo, bajo la Terceridad: “(...) el modo de ser de aquello que es tal como es al relacionar una segunda y una tercera cosas entre sí". El signo puede entenderse como una unidad que se articula, por un lado, con la imaginación, en tanto es un Ícono que afecta al cuerpo y, por otro, con el

\footnotetext{
${ }^{6}$ Se agradece al Dr. Juan Vicente Cortés, especialista en Spinoza, quien hace notar personalmente un problema con la traducción de Atilano Domínguez, quien traduce la expresión latina "non satis", que literalmente significa "no suficientemente", por "con la debida cautela", en vez de "sin la suficiente cautela".

${ }^{7}$ Pierce señala que por su propiedad dinámica un Ícono puede ser tanto un cualisigno, esto es: “... una cualidad que es un Signo. No puede actuar verdaderamente como un signo hasta tanto no esté formulado; pero la formulación no tiene relación alguna con su carácter en tanto signo" (Pierce, 1974, pág. 27): como un sinsigno, a saber "... una cosa o evento real y verdaderamente existente que es un signo. Puede serlo únicamente a través de sus cualidades; de modo tal que involucra a un cualisigno o, en realidad, varios cualisignos. Pero esos cualisignos son de una naturaleza peculiar y sólo forman un signo cuando están efectivamente formulados o encarnados" (Pierce, 1974, p. 29).

${ }^{8}$ El signo en tanto Índice puede ser un sinsigno y/o un legisigno, por ejemplo: un nombre propio o el síntoma de una enfermedad, siendo el síntoma un legisigno y el caso, la enfermedad un sinsigno. (Pierce, 1974, p. 94).

${ }^{9}$ También denominado Legisigno, esto es cuando considerado en sí mismo tiene “...la naturaleza de un tipo general" (Pierce, 1974, p. 93) o, en otras palabras, cuando es "una Ley que es Signo" (Pierce, 1974, p. 29), enfatizando en su carácter convencional.
} 
entendimiento en tanto representa, bien sea, un Índice o un Símbolo, esto es, según sea un signo determinado por un objeto dinámico que está en una relación real con él o en cuanto a cómo es interpretado, respectivamente. Así, un Índice es a su vez un legisigno, por ejemplo, la presencia del síntoma (un legisigno) de una enfermedad es también un índice; mientras que un Símbolo es necesariamente un legisigno que depende de una convención o un hábito de su interpretante (Pierce (1974), p. 94).

A propósito de lo anterior, el signo en Spinoza puede interpretarse semióticamente como una unidad que se articula, por un lado, con la imaginación en tanto es una imagen (un Ícono) y, por el otro, con el entendimiento, en tanto representa una palabra ligada a la imagen (o Índice) o una palabra que convencionalmente representa una idea que, a su vez, denota un objeto (un Símbolo). Desde el punto de vista gnoseológico, el signo, como representación de la imagen, forma parte del conocimiento de opinión o imaginativo; mientras que, como representación de la palabra en tanto vinculada a la idea, pertenece al conocimiento de razón.

Así se entiende que tras el locus fonético "pomun”, el hombre romano de Spinoza pasa, en primer lugar, a la imagen de una fruta $\mathrm{y}$, en segundo lugar, a la idea de la fruta cuya palabra es pomun, conforme ha ordenado varias imágenes de la misma fruta en su memoria (E2p18escB).

Una interpretación semiótica del signo en Spinoza es también capaz de explicar la equivocidad del signo, esto es, por qué la palabra "caballo" es interpretada por el soldado como relativa a la guerra, mientras que, para el campesino representa el arado; considerándolo, desde un punto de vista semiótico, dentro del ámbito de la pragmática, mientras que, desde el punto de vista ontológico, en tanto constituye una imagen que afecta a los cuerpos, como correspondiente al atributo extensión; y en tanto palabra, como parte del atributo pensamiento. Lo cual estaría, además, en conformidad con la conocida tesis del paralelismo spinoziano.

No obstante, surge un inconveniente con esta interpretación, a saber, dar cuenta de cómo puede ser objeto del entendimiento algo tan imperfecto, confuso y equívoco como los signos en tanto palabras del lenguaje común. Una posible respuesta a ello sería argumentar que el signo deja de ser un mero Ícono en tanto supera la esfera del cuerpo y sus afecciones, esto es, en tanto se convierte en Índice o legisigno ${ }^{10} \mathrm{y}$, en consecuencia, puede ser objeto del entendimiento. Ahora bien, en tanto el signo está en la fase de Segundidad, esto es, en tanto es un Índice, puede no haberse desprendido aún de su apariencia como Ícono, y seguir siendo entonces un sinsigno, -o más propiamente, lo que Pierce llama un 'índice-sinsigno'-. De manera que esta interpretación es viable, si y solo si,

\footnotetext{
${ }^{10}$ Ver nota anterior.
} 
el entendimiento, de acuerdo a Spinoza, está en capacidad de modificar estos 'índice-sinsigno' para que resignifiquen las cosas adecuadamente, esto es, de acuerdo al entendimiento.

Sobre este particular, existe una interesante discusión entre los intérpretes de Spinoza respecto a si el entendimiento puede mejorar y entender las cosas de manera afortunada y sin error o, por el contrario, le es imposible mejorar por la sencilla razón de que no lo necesita. El meollo de esta discusión se encuentra en la traducción de la palabra latina emendatio, esto es, si se entiende como medendi intellectus o expurgandi intellectus. (Cf. Eisenberg (1971), p. 178). Esta, aunque es una discusión interesante, excede de los propósitos del presente trabajo, a saber, plantear una interpretación semiótica del signo en Spinoza que permita expresar las verdades filosóficas de la Ética.

\section{Conclusiones}

Tras haber analizado las posiciones exegéticas de David Savan, G.H.R. Parkinson y Mogens Laerke, las cuales, a pesar de sus notables diferencias, plantean un problema en común, a saber, el problema de la inadecuación del lenguaje en Spinoza para trasmitir verdades filosóficas por estar vinculado en su génesis al conocimiento de imaginación; en este trabajo se concluye que: (i) la interpretación semiótica de las palabras en tanto signos en Spinoza aquí propuesta permite responder a las dificultades que surgen de una interpretación del lenguaje en Spinoza restringida a una dimensión exclusivamente semántica, esto es, a una interpretación de las palabras cuyo uso se agota en su significado. Logrando con ello, (i.i) dar cuenta del proceso o tránsito de las palabras en tanto signos, desde que estos son meras imágenes que acontecen a los cuerpos (Íconos), pasando por la transformación de los signos en tanto estos son palabras (Índices) asociadas por determinaciones psicológicas, es decir, inductivamente, a determinadas imágenes en la mente (Índice-sinsigno), hasta llegar a ser propiamente ideas en el entendimiento (Símbolos); de lo que se sigue que un signo podría ser resignificado, adecuándolo al objeto de conformidad con la razón y; (i.ii) transformar las palabras en tanto signos en un signo de terceridad peirceano, que represente como argumento las verdades de la filosofía, haciendo viable la expresión por medio del lenguaje del proyecto de vida planteado por el filósofo holandés tanto en Ética como en el TRE. 


\section{BIBLIOGRAFÍA}

Aristóteles (1978): Acerca del alma. (Patricio de Azcárate, Trad.): Losada.

De Djin, H. (1986): “Conceptions of Philosophical Method in Spinoza: Logica and Mos Geometricus" The Review of Metaphysics, 40, 1, pp. 55-78.

De Djin, H. (1996): Spinoza: The Way to Wisdom. Indiana: Purdue University Press.

Eisenberg, P. D. (1971): "How to Understand De Intellectus Emendatione". Journal of the History of Philosophy, 9, 2, pp. 171-191.

Hampshire, S. (1982): Spinoza. V. Peña, trad. Madrid: Alianza.

Laerke, M. (2014): “Spinoza's Language”. Journal of the History of Philosophy, 52, 3, pp. 519-547.

Maidansky, A. (1998): “The Reform of Logic in Descartes's and Spinoza's Works". Russian Studies in Philosophy, 37, 2, pp. 25-44.

Parkinson, G.H.R. (1969): "Language and knowledge in Spinoza". Inquiry: An Interdisciplinary Journal of Philosophy, 12, 1-4, pp. 15-40.

Parkinson, G.H.R. (1972): "Truth and Falsity in Spinoza”, en S. Kashap (1972): Studies in Spinoza: Critical and Interpretative Essays, pp. 212-235. S. Kashap (ed.). Los Ángeles: University of California Press.

Pierce, C. S. (1974): La ciencia de la semiótica. Buenos Aires: Nueva Visión.

Savan, D. (1972): “Spinoza and Language”, en S. Kashap (1972), pp. 236-248.

Spinoza, B. (2000): Ética demostrada según el orden geométrico. A. Domínguez, trad. Madrid: Trotta.

Spinoza, B. (2008): Tratado de la reforma del entendimiento ( $1^{\mathrm{a}}$ ed.), B. Eremiev \& L. Placencia, trads., Buenos Aires: Colihue.

Spinoza, B. (2010): Tratado Teológico Político (5ta ed.). E.T. Galván, trad., Madrid: Tecnos.

Vinciguerra, L. (2012): “Mark, Image, Sign: A Semiotic Approach to Spinoza”, European Journal of Philosophy, pp.130-144. Oxford: Blackwell Publishing. 